\title{
IMPLANTAÇÃO DE TÉCNICAS DE MANUTENÇÃO AUTÔNOMA EM UMA CÉLULA DE MANUFATURA DE UM FABRICANTE DE MÁQUINAS AGRÍCOLAS
}

\section{IMPLEMENTATION OF AUTONOMOUS MAINTENANCE TECHNIQUES IN A MANUFACTURING CELL OF A AGRICULTURAL MACHINERY MANUFACTURER}

\author{
Ivo Luis Nunes* E-mail: ivo.nunes@hotmail.com \\ Miguel Afonso Sellitto*E-mail: sellitto@unisinos.br \\ *Universidade do Vale do Rio dos Sinos (UNISINOS), São Leopoldo, RS
}

\begin{abstract}
Resumo: O objetivo deste artigo foi descrever um caso de aplicação de manutenção autônoma em uma área piloto de uma empresa do ramo metal mecânico. O método de pesquisa foi o estudo de caso único em uma célula de produção com três centros de usinagem em uma empresa fabricante de máquinas agrícolas. Os objetivos secundários do artigo foram: descrever o cenário em que a aplicação ocorreu; descrever procedimentos e resultados; e analisar os benefícios obtidos, apresentando resultados antes e depois da implementação. Os principais resultados da aplicação foram o aumento nos tempos médios entre falhas das máquinas, a redução nos tempos médios até o reparo das máquinas, a redução de refugos e retrabalhos na célula e a redução dos custos de manutenção. Como consequência destes avanços, houve expressivo aumento na eficiência global da célula de $78 \%$ para $88,3 \%$, o que pode ser considerado desempenho de classe mundial. Outros ganhos foram a redução de estoque intermediário, de tempo de set-up e da área física ocupada.
\end{abstract}

Palavras-chave: Manutenção autônoma. OEE. Células de fabricação.

Abstract: The purpose of this article was to describe a case of autonomous maintenance implementation in a pilot area of a metal mechanical company. The research method was the single case study in a production cell with three machining centers in agricultural machinery manufacturer. The secondary objectives of the article were: describe the scenario in which the application occurred; describe procedures and results; and analyze the benefits obtained, showing results before and after implementation. The main results of the application were the increase in the mean times between failures, the reduction in mean time to repair, the reduction of waste and rework in the cell, and the reduction of maintenance costs. After the improvements, there was significant increase in the overall efficiency of the cell, from $78 \%$ to $88.3 \%$, which can be considered world-class performance. Other relevant gains were: work in process reduction, set-up time reduction, and physical occupied area reduction.

Keywords: Autonomous maintenance. OEE. Manufacturing cells.

\section{INTRODUÇÃO}

$\mathrm{Na}$ segunda metade do século $\mathrm{XX}$, setores da indústria japonesa modificaram suas técnicas de gestão de produção, anteriormente baseadas principalmente em técnicas observadas em fábricas americanas. Após alguns 
anos, os produtos japoneses tornaram-se conhecidos por sua qualidade superior, sendo exportados em grande escala para países ocidentais. Em decorrência disso, as técnicas de gestão japonesa chamaram a atenção do mundo todo (NAKAJIMA, 1984).

Os administradores concordavam que a fórmula para estabelecer os preços em produtos era: [custo + lucro] = preço de venda (SHINGO, 1996). No entanto, a equação apresentada pela gestão japonesa é: [preço - lucro] = custo, sendo que o alvo para aumentar o lucro era através da redução do custo, já que o preço é determinado pelo mercado, tal visão requer claramente a necessidade continua de redução de custo e em consequência a eliminação dos desperdícios (SHINGO, 1996).

Um conceito de gestão utilizado no Japão foi o de Produção Enxuta, segundo o qual, na produção em massa, muitas atividades da manufatura não agregavam valor ao produto nem interessavam ao cliente, por isso precisavam ser eliminadas ou reduzidas, tal como a manutenção de elevados estoques de materiais em processamento ou acabados. Uma das causas da existência de estoques eram as quebras inesperadas de equipamento. Logo, para um sistema de estoque zero, deve ser priorizada a eliminação de quebras inesperadas (SHINGO, 1996). Para tanto, era necessário prestar mais atenção à gestão da manutenção industrial (SELLITTO et al., 2002). A gestão da manutenção permite focalizar apenas nas ações com mais chances de bom resultado com baixo esforço (SILVA FILHO e SELLITTO, 2014).

Uma das técnicas de gestão da manutenção que podem ser úteis em produção enxuta é a metodologia TPM (Manutenção Produtiva Total). Para Nakajima (1989), a TPM corresponde à busca da falha zero nos processos, da quebra zero nas máquinas, e do defeito zero nos produtos. Além disso, a TPM oferece um fator chave no desenvolvimento e na otimização do desempenho fabril: a maximização da eficiência das máquinas (BAMBER et al., 1999). A TPM estabelece a integração total entre o homem, a máquina, e a empresa; com a TPM, a manutenção dos meios de produção passa a ser preocupação e ação de todos (NAKAJIMA, 1993; WIREMAN, 1998). Uma das exigências para o sucesso de programas de TPM é o apoio da alta e média gerência, pois estas determinam as prioridades empresariais (TAKAHASHI e OSADA, 1993). 
Segundo Nakajima (1989), um dos objetivos de atividades conduzidas pela TPM no ambiente fabril é aumentar a produtividade, minimizando entradas e maximizando saídas. Outro objetivo é descobrir falhas escondidas, que podem passar despercebidas pela equipe de operação, caso esta não tenha desenvolvido um olhar crítico sobre o estado de uso do equipamento. É premissa da TPM a participação de todos, desde a alta administração até os colaboradores de chão de fábrica. A metodologia deve ser implantada e executada por meio de atividades em pequenos grupos (SUZUKI, 1994). Desenvolvendo e treinando as pessoas, é possível realizar mudanças nas máquinas e nos equipamentos. Modificando máquinas e equipamentos, há melhoria no resultado global (KARDEC e NASCIF, 2001).

A TPM é sustentada por pilares de desenvolvimento, apresentados por Nakajima (1989). No início, eram cinco os pilares. Posteriormente, os pilares aumentaram para oito, ao se incluírem abordagens administrativas, de qualidade, segurança, saúde e meio ambiente. Tais inclusões permitiram a extensão da TPM a setores de administração da atividade fabril.

Para este artigo, o pilar de mais interesse é a Manutenção Autônoma (MA), se bem que se reconheça a importância dos demais pilares (CONCEIÇÃO JR. e SILVA, 2010). O motivo para esta escolha é que foi por este pilar que a empresa estudada decidiu iniciar sua jornada em direção à TPM. Esta escolha é coerente com o dizer de Suzuki (1994), que afirma que, via de regra, a Manutenção Autônoma torna-se o pilar mais importante e de mais resultado observável em programas de implantação de TPM.

Sendo assim, o objetivo deste artigo é descrever um caso de aplicação de manutenção autônoma em uma área piloto de uma empresa do ramo metal mecânico. O método de pesquisa foi o estudo de caso único. Os objetivos secundários são: descrever o cenário em que a aplicação ocorreu; descrever procedimentos e resultados; e analisar os benefícios obtidos, apresentando resultados antes e depois da implementação. Este artigo limita-se a uma célula piloto, constituída de três centros de usinagem.

O restante do artigo está organizado em: revisão; pesquisa; resultados; e considerações finais. 


\section{SISTEMA TOYOTA DE PRODUÇÃO E TPM}

Nos últimos anos da década de 1940, houve importante transformação na Toyota Motors, que influenciou várias áreas da indústria japonesa. Toyoda Kiichiro (1894 - 1952), então presidente da Toyota Motors, afirmou na época: "Alcancemos os Estados Unidos em três anos, caso contrário, a indústria automobilística do Japão não sobreviverá" (OHNO, 1997, p.25). Segundo Ohno (1997), para cada atividade executada por um trabalhador alemão eram necessários três japoneses, e que a razão entre as forças de trabalho alemã e americana também era de um para três. Então, a razão entre trabalhadores japoneses e americanos era de um para nove. A evidência de que, no sistema de produção vigente, não haveria como aumentar a produtividade em quase dez vezes fez crer que havia algo sendo desperdiçado pelos japoneses. Assim, eliminados os desperdícios, a produtividade deveria aumentar. Foi essa ideia que marcou o início do Sistema Toyota de Produção.

Após a crise do petróleo de 1974, os resultados obtidos pela Toyota Motors atraíram a atenção da indústria ocidental (SHINGO, 1996). A partir da década de 1980 ficou claro que existia algo em especial na qualidade dos produtos e na eficiência da indústria japonesa (LIKER, 2005).

Frequentemente, o Sistema Toyota de Produção (TPS) é considerado o motivo do sucesso da Toyota e muitas obras foram publicadas sobre o tema, relatando seus métodos e ferramentas para obter produção enxuta com qualidade e lucratividade, porém o desempenho da Toyota decorre da transformação da excelência operacional em uma arma estratégica (SHINGO, 1996; LIKER, 2005). Portanto, o sucesso da Toyota origina-se de uma filosofia baseada na compreensão das pessoas e da motivação humana. Essa é uma diferença entre Sistema Toyota de Produção e Modelo Toyota (LIKER, 2005).

O Sistema Toyota de Produção enfatiza a produção sem estoque ou com estoque zero. Quebras ou falhas de máquinas resultam em operações ineficientes, e essas geram estoques para compensar as falhas de máquinas e produtos defeituosos (SHINGO, 1996). As atividades que não agregam valor ao cliente foram chamadas de desperdício e classificadas em: i) superprodução; ii) estoque; iii) transporte; iv) movimentação; v) defeitos; vi) processos desnecessários; e vii) espera (OHNO, 1997). 
Figura 1 - Sistema Toyota de Produção e TPM

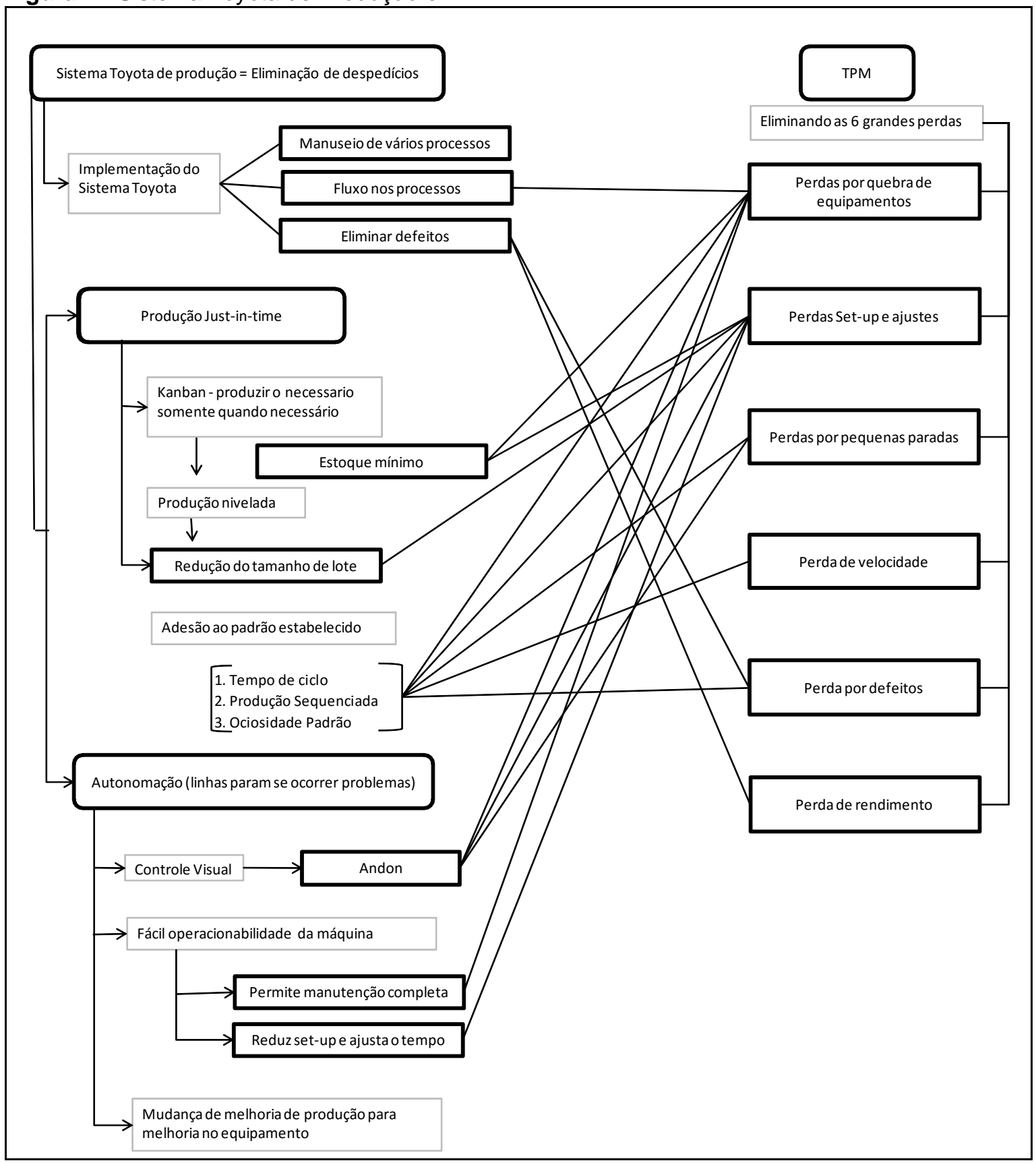

Fonte: Adaptado de Nakajima (1989) e Shingo (1996)

Enquanto o objetivo de zero defeito busca prevenir que ocorram defeitos de qualidade em produtos, a TPM busca prevenir que haja falhas nos equipamentos, ou seja, busca a zero quebra. Em ambas as filosofias de gerenciamento, o operador é responsável pelas inspeções, trata-se de um sistema preventivo para eliminar defeitos e desperdícios (NAKAJIMA, 1988). A introdução da TPM pode ajudar a gerenciar e a promover a agilidade e a flexibilidade da produção (BOER e GERTSEN, 2003). 
A Figura 1 representa como a TPM pode auxiliar o Sistema Toyota de Produção a alcançar uma produtividade superior. Esta integração se dá por meio de metas de zero defeito e do controle das seis grandes perdas combatidas pela TPM. Estas perdas serão detalhadas na continuidade do artigo.

\subsection{Objetivos da TPM}

Os objetivos da TPM foram traçados pelo JIPM (Japan Instituite of Plant Maintenance) e são: i) Maximizar a eficiência dos sistemas produtivos; ii) Minimizar perdas, estabelecendo metas orientadas ao zero acidente, zero perdas e zero defeitos; iii) Envolver todos os departamentos na implantação, incluindo novos produtos, vendas e administração; iv) Envolver todos os funcionários desde a alta gerência até os operadores de chão de fábrica; e v) Agir por atividades de pequenos grupos (SUZUKI, 1994). Assim, a meta a ser alcançada é o rendimento global, por meio de ações de manutenção conduzidas com a participação de todos (NAKAJIMA, 1989).

Sistemas produtivos têm como meta maximizar performances, o que é obtido por meio da geração do máximo de resultados (outputs) possíveis com o mínimo de consumo de insumos (inputs). Para tanto, muitas vezes, em processos contínuos ou em linha, como o estudado neste artigo, é necessário focar naquelas instalações cujas falhas causam danos muito maiores na produção do que falhas em outros pontos do sistema (SELLITTO, 2002). Pachco et al. (2012) chamam estas instalações (máquinas ou conjunto de associado de máquinas) de gargalos ou restrições. Esses autores afirmam que técnicas, tais como o cálculo do OEE, que foi usada neste artigo, são mais eficazes aplicadas nos gargalos do que fora deles. Isto não significa que se persiga necessariamente uma maior produção absoluta, mas uma maior produtividade, advinda da integração entre bons resultados em termos de custo, qualidade, prazo de entrega, e segurança, aliados a um bom ambiente de trabalho e a um cenário de melhorias contínuas, a fim de reunir todos os fatores que resultem em uma maior motivação para a realização de um serviço ou fabricação de um produto (NAKAJIMA, 1989). 
Para aumentar a produtividade fabril, e por consequência os resultados integrados de custo, qualidade, prazo de entrega, e segurança, Nakajima (1989) definiu seis grandes perdas em equipamentos, que devem ser combatidas em programas de implantação da TPM. As seis perdas são descritas no Quadro 1.

Quadro 1- As seis grandes perdas de produtividade combatidas pela TPM

\begin{tabular}{ll}
\hline Tipos de Perdas & \multicolumn{1}{c}{ Descrição } \\
\hline $\begin{array}{l}\text { Perda por quebra } \\
\text { Perda devido a } \\
\text { setup e ajustes }\end{array}$ & $\begin{array}{l}\text { São as perdas de tempo e de materiais devida à falha ou à quebra do } \\
\text { equipamento. } \\
\text { tempo de preparação para trocas serve para preparar a produção } \\
\text { subsequente. }\end{array}$ \\
$\begin{array}{l}\text { Perdas por } \\
\text { pequenas } \\
\text { paradas e } \\
\text { trabalho lento ou } \\
\text { em vazio }\end{array}$ & $\begin{array}{l}\text { São paradas nas quais o equipamento fica sem operar, mais denominada } \\
\text { representa uma quantidade significativa em longo prazo. }\end{array}$ \\
$\begin{array}{l}\text { Perdas por } \\
\text { redução de } \\
\text { velocidade }\end{array}$ & $\begin{array}{l}\text { É a diferença entre a velocidade real do equipamento e a velocidade } \\
\text { projetada, na maioria das vezes em função das condições inadequadas às } \\
\text { quais o equipamento está submetido. }\end{array}$ \\
$\begin{array}{l}\text { Perdas por } \\
\text { problemas na } \\
\text { qualidade }\end{array}$ & $\begin{array}{l}\text { Estas perdas estão relacionadas à descoberta de produtos com defeitos de } \\
\text { qualidade, ocasionando retrabalho ou até eliminação da peça ou produto. } \\
\text { Normalmente quando a origem do defeito é habitual decorre de algum grau } \\
\text { de deterioração do equipamento ao qual não foi dada importância. }\end{array}$ \\
$\begin{array}{l}\text { Perdas de } \\
\text { rendimento ou na } \\
\text { partida }\end{array}$ & $\begin{array}{l}\text { Estão relacionadas a restrições técnicas do equipamento, que acarretam } \\
\text { em um período de estabilização das condições dos equipamentos após uma } \\
\text { parada. }\end{array}$ \\
\hline
\end{tabular}

Fonte: Nakajima (1989)

Um modo de medir as melhorias oportunizadas por programas de implantação de TPM é por meio do indicador OEE (Overall Equipment Effectiveness) (ALBERTIN et al., 2012). O indicador OEE é uma combinação linear de resultados intermediários de disponibilidade, de performance e de qualidade $(\mathrm{KOCH}, 2007)$, representando uma taxa global de utilização de um dado equipamento (FERREIRA et al., 2012). A OEE pode ser considerada como uma medida de eficiência global de um certo equipamento e sua medição pode informar acerca da eficácia com que este equipamento está sendo gerenciado (ZATTAR et al., 2011). A OEE é especialmente útil em manufatura 
de alto volume de produção, tal como na empresa estudada neste artigo (RON e ROODA, 2005).

\subsection{Os Oito Pilares da TPM}

A TPM é sustentada por oito pilares, apresentados e descritos por Nakajima (1989) no início do desenvolvimento da TPM. Esses oito pilares, em conjunto, são essenciais para combater as seis grandes perdas e obter sucesso no programa da TPM (NAKAZATO, 1999). Todos devem ser implementados, embora se reconheça que, segundo o caso, alguns podem ter mais importância do que outros (SUZUKI, 1994).

A Figura 2 apresenta os oito pilares do TPM.

Figura 2 - Os oito pilares da TPM

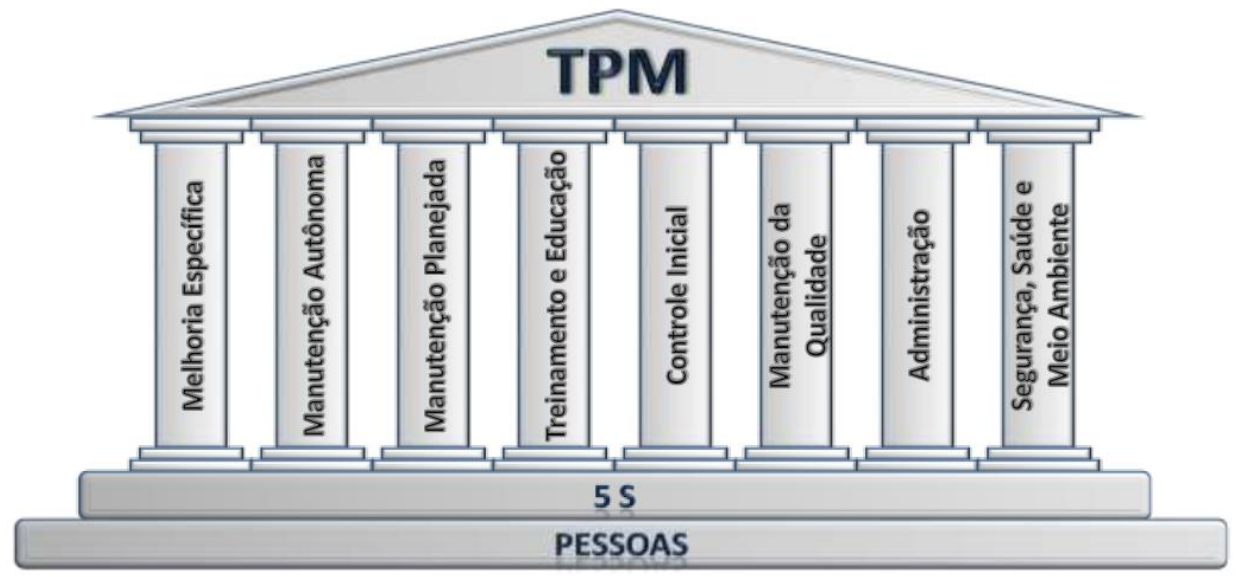

Fonte: Adaptado de Nakajima (1989) e Nakazato (1999)

$\mathrm{Na}$ base da figura estão as pessoas, desde os operadores até a alta gerência, pois o sucesso da TPM depende da participação e conscientização de todos. Está presente também a filosofia do $5 \mathrm{~S}$, fundamental para qualquer iniciativa de mudança. Quando os operadores são treinados para entender os princípios por trás das falhas nos equipamentos, o $5 S$ ganha novo impulso e passa a ser praticado com mais intensidade nas partes críticas dos equipamentos, contribuindo para a obtenção de resultados (XENOS, 1998).

O Pilar Melhoria Específica é voltado a melhorias para eliminar as perdas. É focar a melhoria global do negócio. Deste modo, procura-se reduzir os problemas para melhorar o desempenho com base na organização de células de trabalho ou linhas de montagem com o objetivo de encontrar falhas 
escondidas pela desorganização, que não são visíveis em uma primeira e superficial abordagem (WAKJIRA e SINGH, 2012).

O Pilar Manutenção Autônoma é voltado para prevenir a deterioração forçada dos equipamentos. Autogerenciamento e controle, liberdade de ação, elaboração e cumprimento de padrões, conscientização da filosofia da TPM. Este pilar desenvolve o operador para trabalhar em equipe e conhecer melhor o equipamento realizando pequenas atividades ligadas à manutenção (WAKJIRA e SINGH, 2012).

O Pilar Manutenção Planejada é voltado para melhorias, visando aumentar a confiabilidade e manutenabilidade buscando a quebra zero. Significa ter realmente o controle da manutenção, o que implica treinamento em técnicas de planejamento, utilização de um sistema mecanizado de planejamento da programação diária e do planejamento de paradas, para que as atividades de manutenção possam ser executadas com qualidade com 0 cumprimento do cronograma (McKONE e CUA, 1998).

O Pilar Educação e Treinamento visa eliminar as lacunas de competências e habilidades, ampliar a capacitação técnica, gerencial, comportamental do pessoal de manutenção e operação, reduzindo o absenteísmo dos funcionários e aumentando a quantidade de sugestões por parte dos colaboradores de chão de fábrica, ou seja, a melhoria continua (SURESH, 2012).

O Pilar Controle Inicial promove melhoria em projetos de equipamentos e produtos garantindo o bom desempenho inicial dos mesmos. Estabelecimento de um sistema de gerenciamento da fase inicial para novos projetos ou equipamentos (SURESH, 2012).

O Pilar Manutenção da Qualidade promove melhorias para prever defeitos de qualidade antes que ocorram, realizando a transição da qualidade reativa para qualidade proativa (controle de qualidade para garantia da qualidade). Estabelece-se para tanto um programa de zero defeito (KATKAMWAR et al., 2013).

O Pilar Áreas Administrativas objetiva estabelecer melhorias para eliminar perdas associadas à comunicação e analise de procedimentos. Estabelece um programa de manutenção produtiva total nas áreas administrativas, visando o aumento de sua eficiência e autonomia (RAPOSO, 
2011). Pode incluir apoio a serviços técnicos e exercício de garantias oferecidas por fabricantes de máquinas (BORCHARDT et al., 2008; BORCHARDT et al., 2010).

O Pilar Segurança e Meio Ambiente objetiva estabelecer melhorias para eliminar riscos de acidentes, exposição e poluição. Estabelece um sistema de saúde, segurança e meio ambiente. Este pilar tem papel ativo em cada um dos demais pilares como uma base conceitual (KATKAMWAR et al., 2013).

\subsection{Manutenção Autônoma}

A Manutenção Autônoma (MA) é um dos pilares mais importantes de sustentação da TPM (SUZUKI, 1994). Pode ser entendida como o processo de capacitação de operadores, tornando-os aptos a promover mudanças em equipamentos isolados e em sistemas de produção que garantam altos níveis de produtividade no ambiente de trabalho (NAKAJIMA, 1989).

A MA inclui limpeza, treinamentos e formação de equipes e uma estratégia para o envolvimento do operador com o equipamento (McKONE e CUA, 1999). A meta fundamental da manutenção autônoma é evitar que, durante o dia-a-dia da produção, os equipamentos se deteriorem, detectando e tratando suas anomalias em estágios iniciais, antes que estas se desenvolvam e resultem em falhas (XENOS,1998). Em suma, toda falha visível se origina em algum tipo de anomalia, a princípio invisível para o operador e que pode e deve ser identificada por uma rotina de inspeções.

Para Tavares (1999), a manutenção autônoma é uma estratégia simples e prática que envolve os operadores nas atividades de manutenção, principalmente limpeza, lubrificação, e inspeções visuais, tendo como base a prática contínua e sistemática do 5S. Praticar a manutenção autônoma significa desenvolver um operador com alto nível de conhecimento sobre seu equipamento para que ele possa atuar como um sensor para detectar anomalias com antecedência e relatá-las, se comprometendo e zelando pelo equipamento (XENOS, 1998).

Segundo Nakajima (1989) e Xenos (1998), a implementação da manutenção autônoma passa por sete etapas e deve ser feita preferencialmente em atividades de pequenos grupos (APG): 
- Etapa 1: Fazer a limpeza inicial, reforçando o conceito de que a limpeza é uma inspeção.

- Etapa 2: Combate às causas dos problemas e tratamento diferenciado aos locais de difícil acesso, ensinando os operadores como identificar outras causas de deterioração para problemas mais frequentes e crônicos.

- Etapa 3: Elaboração dos padrões de limpeza e de lubrificação, com o objetivo de controlar atividades básicas para evitar a deterioração do equipamento.

- Etapa 4: Inspeção geral, desenvolvendo habilidades de inspeção visual geral em partes principais dos equipamentos para detectar anomalias ou falhas ocultas.

- Etapa 5: Inspeção autônoma, utilizando as listas de verificações e procedimentos operacionais com a máxima efetividade.

- Etapa 6: Organização e ordem, visando à abrangência da manutenção autônoma através do melhor gerenciamento do local de trabalho.

- Etapa 7: Consolidação da manutenção autônoma, revisando as ações tomadas, ajudando a implementar melhorias para estender a vida útil do equipamento.

A expressão manutenção autônoma está relacionada às atividades de manutenção iniciadas pela gerência e executadas em pequenos grupos.

A atividade de pequenos grupos é uma característica peculiar no Japão, tais como atividades de círculo de controle de qualidade (CCQ), atividades de grupos ZD (zero defeito) e atividades JK (Jishu Kanri ou controle autônomo) (NAKAJIMA, 1988). Este tipo de atividade passou a ser mais difundido, consolidando a ideia de que cada um executa e controla o seu trabalho, sendo assim a Manutenção Autônoma é responsável pela mentalidade do conceito que era "eu fabrico, você conserta" para "do meu equipamento cuido eu" (PETTER et al., 2011). O objetivo das atividades de pequenos grupos tem como base melhorar o desempenho do equipamento através da comunicação e eliminar possíveis falhas e problemas com o equipamento (SWANSON, 2001). 
Muitos especialistas dizem que a chave do sucesso em pequenos grupos de atividades depende de três condições: motivação, habilidade e ambiente de trabalho favorável (NAKAJIMA, 1988). Por isso, a primeira responsabilidade da gerência é prover treinamento especial, desenvolvendo uma força de trabalho capaz, motivada e realmente composta por trabalhadores que possuam habilidades para executar a manutenção autônoma (NAKAJIMA, 1988).

As unidades de produção têm estudado e analisado os resultados após implementações da TPM, e o principal benefício alcançado é o aumento da produtividade como resultado da implementação do TPM (WAKJIRA e SINGH, 2012). Com as atividades da Manutenção Autônoma e o investimento em treinamentos operacionais e educacionais para o operador, a eficácia global do equipamento melhorou e a deterioração do equipamento foi reduzida após o impulso moral do operador (WAKJIRA e SINGH, 2012).

A lubrificação autônoma é uma ferramenta integrante do pilar da Manutenção Autônoma e é importante para a metodologia da TPM, visto que torna a conservação do equipamento responsabilidade da produção (GOMES, 2012). Segundo Lazim et al. (2008), a concepção da TPM é fácil e óbvia, mas alguns cuidados precisam ser levados em conta, pois existem algumas deficiências assinaladas. Gestores tendem a se concentrar nos resultados iniciais, em vez de atividades voltadas para a redução das perdas no longo prazo. Conforme relatado por Monteiro Jr. et al. (2012), em aplicações da TPM, mesmo ganhos aparentemente menores, tais como o aumento de $1 \% \mathrm{em}$ relação ao OEE dos equipamentos, pode despertar interesse na alta administração de corporações e incentivar a extensão e disseminação da prática na empresa.

\section{A PESQUISA}

O objetivo deste artigo é descrever um caso de aplicação de manutenção autônoma em uma área piloto de uma empresa do ramo metal mecânico, fabricante de máquinas agrícolas. 0 método de pesquisa foi 0 estudo de caso único. Como fontes de evidências, foram usados documentos 
da empresa, reuniões com gestores e com os trabalhadores de chão de fábrica e observação participante do pesquisador.

A empresa estudada é uma das plantas de um grupo internacional, com matriz nos Estados Unidos, uma fabricante e distribuidora conhecida globalmente no mercado agrícola. No Brasil, o grupo possui três unidades fabris no Rio Grande do Sul e duas em São Paulo, atendendo 2.600 concessionárias. A unidade em que foi realizado o estudo de caso, produz tratores agrícolas, tratores industriais, retroescavadeiras e pulverizadores, em uma área de aproximadamente $200.000 \mathrm{~m}^{2}$. Conta com 1.600 funcionários e uma capacidade de produção mensal de 2.700 unidades.

O método do trabalho foi:

- Revisão bibliográfica sobre Produção Enxuta e TPM;

- Planejamento do método de implantação baseado na revisão e nas características culturais da organização;

- Citação das atividades conduzidas no parque fabril;

- Evidências dos resultados obtidos até o momento;

- Análise dos resultados parciais e projeção de um estado futuro.

\subsection{O Caso}

A TPM contribuiu para que a empresa alcançasse suas metas de qualidade, eficiência e custos, planejadas pela corporação. A meta global corporativa é ser reconhecida como número um em qualidade no mercado de máquinas agrícolas até 2015. Várias metodologias foram adotadas na busca desta meta. Para este artigo interessa apenas a implantação da TPM e em particular a implantação da Manutenção Autônoma (MA), que foi o primeiro passo do programa de implantação da TPM na empresa. Foram adotados os doze passos propostos por Nakajima (1988), adaptados para a cultura da empresa. Os passos foram:

i. Comprometimento da alta administração da empresa;

ii. Divulgação do método;

iii. Definição do comitê responsável pelo programa;

iv. Determinação das políticas e metas básicas; 
v. Definição do plano diretor;

vi. Início propriamente dito da implantação;

vii. Instrução dos operadores;

viii. Definição de procedimentos pelos grupos de trabalho;

ix. Escolha de equipamentos-piloto para medição da eficácia;

x. Desenvolvimento da manutenção autônoma;

xi. Medição dos resultados;

xii. Realização da auditoria e retorno ao início do ciclo.

A análise dos resultados se deu por meio do acompanhamento de quatro indicadores: MTBF, MTTR, OEE, e custos de manutenção.

A cada final de ano, todas as áreas da manufatura da empresa passam por auditoria global, em que o vice-presidente global de melhoria continua verifica e pontua todos os setores da manufatura. Após essa verificação, apresenta para a diretoria da unidade um plano de trabalho para alcançar as metas globais. No final do ano de 2011, o vice-presidente global de melhoria contínua apresentou como meta para 2012 a minimização de estoques entre processos e a implementação do programa TPM na área de usinagem. Foram assinaladas oportunidades de melhoria para a manufatura: grande número de máquinas quebradas, falta de registro e estatísticas destas quebras, má condições das máquinas e falta de instruções para os operadores, gerando então estoques entre processos para justamente para administrar essas falhas.

Com a meta proposta pelo vice-presidente global de melhoria contínua, a diretoria da unidade promoveu uma reunião com os gestores, declarando oficialmente a implantação do programa da TPM na área de usinagem. Com esta medida, o passo (i) de implementação da TPM foi dado.

Os gestores da manutenção e usinagem ficaram responsáveis pela coordenação e implementação da TPM em suas respectivas áreas. $O$ programa ganhou ainda mais força quando as participações de lucros por resultados (PLR) destes gestores foram atreladas ao programa da TPM. $O$ programa teve início em janeiro de 2012, com a definição da equipe composta por profissionais de diversas áreas, que passaram a ser os líderes dos pequenos grupos e os disseminadores conceituais do programa.

Antes de iniciar o primeiro passo do planejamento do programa da TPM, foram promovidas atividades e treinamentos relacionados ao cenário industrial 
atual, composto dos seguintes módulos: 5S, Lean Manufacture, Just-in-time e ferramentas para solução de problemas (diagrama de Ishikawa, diagrama de Pareto, MASP, $5 \mathrm{~W} 2 \mathrm{H}$, entre outros). Estes treinamentos nivelaram 0 conhecimento da equipe de líderes e foram úteis para que todos soubessem o porquê da implantação da TPM. O próximo passo foram os treinamentos relacionados à TPM: definição da TPM, Oito Pilares da TPM, Metodologia de Implementação da TPM e Classificação de Perdas. Com estas medidas, foram implantados os passos (ii) e (iii).

O passo seguinte foi o mapeamento do fluxo de valor da célula. A equipe coletou dados e identificou que o índice de valor agregado era de aproximadamente $0,5 \%$, ou seja, o custo que o cliente pagava pela agregação (transformação) de valor na peça correspondia a apenas $0,5 \%$ do tempo de atravessamento da peça na célula, o resto era desperdício. Também foi possível medir o tempo de atravessamento da célula. Na sequência, a equipe executou a cronoanálise das atividades, identificando expressivas perdas que estavam ocultas na jornada de trabalho dos operadores. Com a cronoanálise, ficou claro o porquê do excesso de WIP: a instabilidade da célula devido às permanentes quebras de máquinas. Também ficou claro que, na célula, havia mais mão de obra do que a necessária, pois a célula estava desbalanceada, e não havia padronização nas atividades, agravado principalmente por sucessivas falhas nos equipamentos.

Com essas informações iniciou-se o $5 \mathrm{~S}$ da célula tendo por ponto de partida o desenho de um estado futuro para a célula, aproximando as ferramentas, dispositivos e instrumentos de medição de qualidade dos operadores para eliminar deslocamentos, já que isso não agrega valor. Pintaram-se com verde, amarelo e vermelho as esteiras que abastecem peças de uma operação para outra, com o objetivo de informar quantas peças eram necessárias entre operações. Também reorganizou-se o lay-out da célula, aproximando as máquinas com objetivo de diminuir o número de operadores e padronizar cada elemento das atividades dos operadores. A padronização das atividades foi documentada e afixada ao lado de cada máquina. Com estas providências, ficou mais fácil tornar permanente a prática, do $5 \mathrm{~S}$, o que passou a ser um objetivo do pessoal da célula de usinagem. 
Os objetivos das reformulações foram determinados pela equipe: redução de falhas nos equipamentos, aumento da eficiência da máquina, alongamento da vida útil do equipamento, ambiente de trabalho mais limpo e organizado, redução de custos da manutenção, mudança cultural e comportamental dos operadores, comprometimento da produção com 0 equipamento, redução de inventário na célula e maior disponibilidade de máquina.

Os operadores foram remanejados e treinados segundo os novos padrões, que incluíram atividades de MA e inspeções de qualidade que os operadores deveriam executar, na quantidade certa, qualidade certa e no momento certo. Durante o treinamento, a equipe também definiu a célula piloto em que o programa deveria iniciar. Esta célula é composta por três centros de usinagem, que usinam a peça denominada trombeta. Com esta medida, implantaram-se os passos: (iv) Determinação das políticas e metas básicas; (v) Definição do plano diretor; (vi) Início propriamente dito da implantação; e (ix) Escolha de equipamentos piloto para medição de eficácia.

Após o treinamento da equipe de líderes sobre princípios da Produção Enxuta e da TPM, iniciou-se a atuação como disseminadores do programa, passando treinamentos para os colaboradores da produção, focando principalmente nas atividades que os operadores devem exercer no programa e na conscientização da importância da manutenção autônoma. Durante o treinamento, foi apresentado aos operadores e líderes de usinagem o Documento de Padronização de Atividades e o Plano de Conservação do equipamento, nos quais informavam a periodicidade e a localização dos pontos de verificação e limpeza com os quais os operadores deveriam atuar, com o objetivo de identificar potenciais falhas no equipamento antes que estes potenciais se tornassem falhas, com máquina produtiva parada para manutenção corretiva.

A Figura 3 apresenta uma folha do Plano de Conservação de um dado equipamento. 
Figura 3 - Plano de Conservação, limpeza e inspeção de máquinas

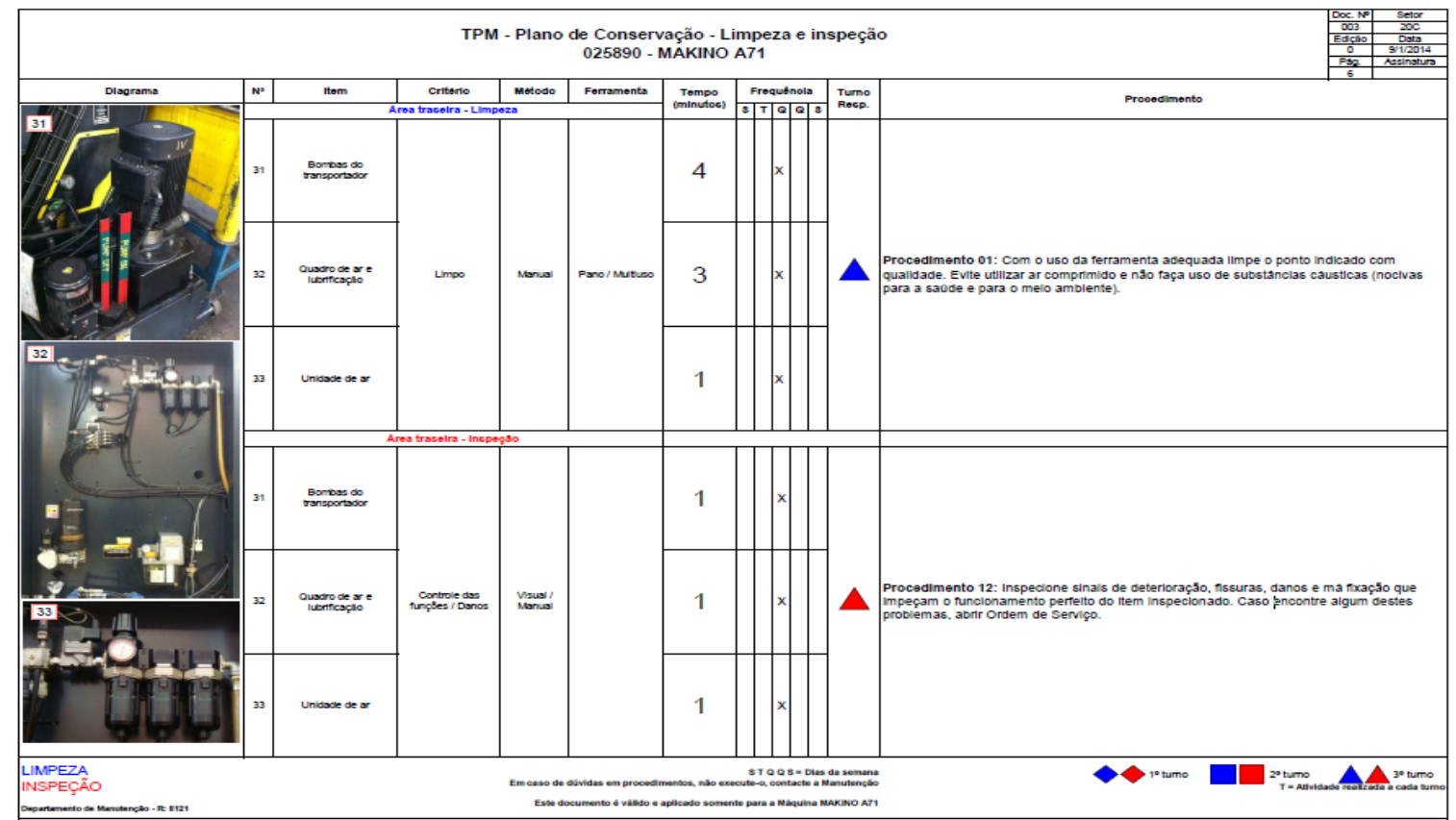

Fonte: Documentação interna da empresa estudada

O time de operadores da célula também recebeu o treinamento de como sinalizar as anomalias encontradas durante as inspeções e verificações. Esta sinalização se dá por um quadro de anomalias que fica na célula. Além de abrir uma ordem de serviço no sistema da empresa, os operadores devem abrir um cartão e colocar no devido lugar do quadro. Este quadro facilita a gestão visual da célula a controlar as demandas da TPM. A Figura 4 apresenta o quadro de gestão visual da TPM e o cartão, respectivamente. 
Figura 4 - Quadro de Gestão Visual da TPM e Cartão de Controle da Manutenção
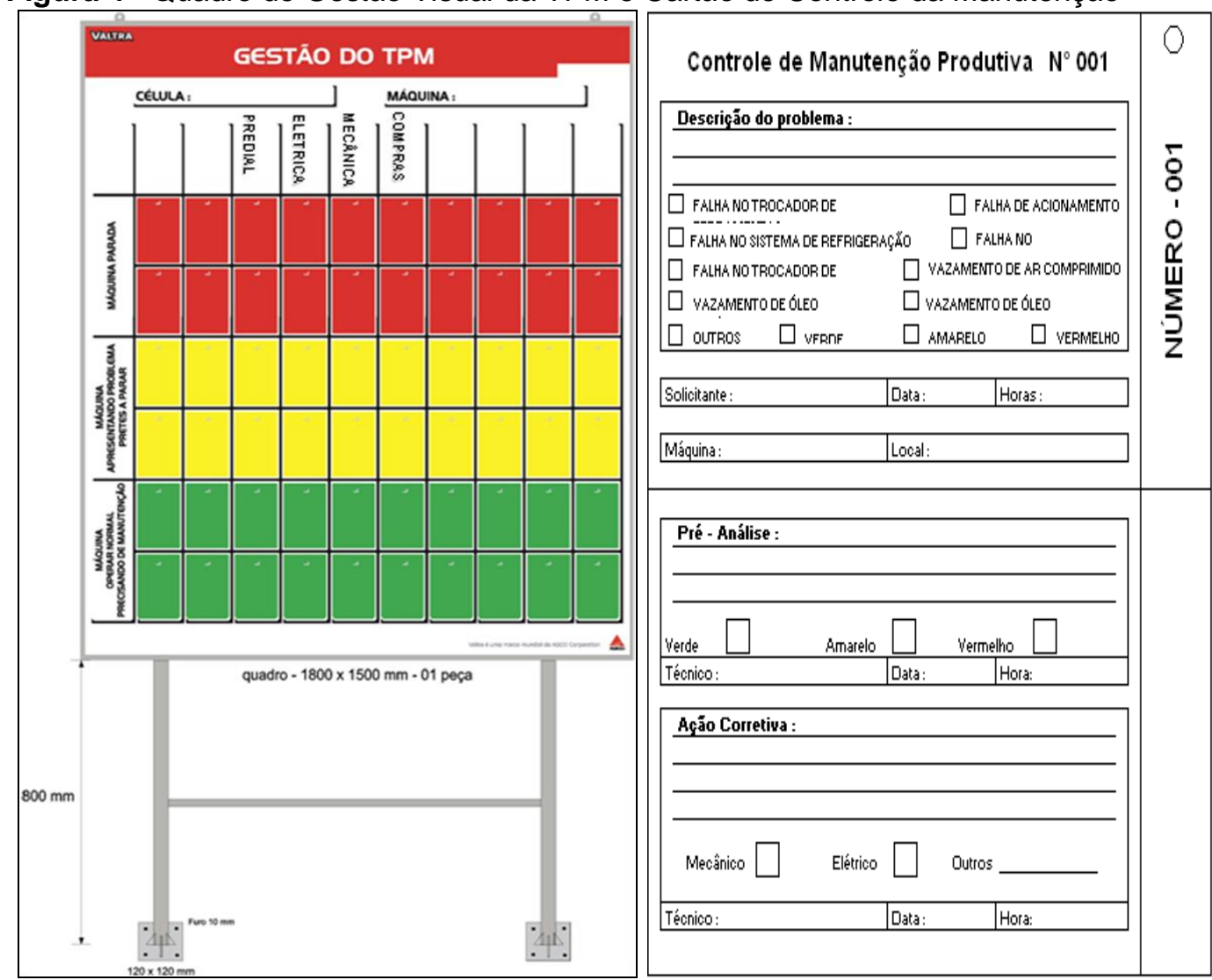

Fonte: Documentação interna da empresa estudada

Com estas medidas, foi implantado o passo: (vii) Instrução dos operadores.

Após todo o grupo estar treinado e a célula piloto definida, foi estipulada uma data para a limpeza inicial do equipamento e sanar dúvidas sobre as atividades e inspeções com as quais os operadores estariam envolvidos e também para promover o início do programa. Este dia foi chamado pelo grupo de "dia D". Durante este dia, o diretor de manufatura e muitos gestores de diferentes áreas da empresa tiveram a oportunidade de ver e entender o que era a TPM. Muitos dos questionamentos por parte da alta gestão e dos próprios operadores foram respondidos pelos manutentores. Com esta etapa, implantaram-se os passos: (viii) Definição de procedimentos pelo grupo de trabalho; e (x) Desenvolvimento da manutenção autônoma.

Após o início da MA, a expectativa da equipe de manutenção era que muitas ordens de serviços fossem abertas, gerando uma alta demanda de atendimento por parte da equipe de manutenção, mas, à medida que o programa evolui, as ocorrências de manutenção corretiva diminuíram. A equipe 
definiu que os resultados seriam avaliados por meio das medições de MTBF (Mean Time Between Failures, tempo médio entre falhas), MTTR (Mean Time to Repair, tempo médio de reparo), indicador OEE, e custo de manutenção emergencial.

Os dados que foram coletados eram baseados em um ano antes do início do programa, utilizando a média do período de um ano após o início do programa. Com esta medida, implantou-se o passo (xi) Medição dos resultados.

Figura 5 - Esquema de interligação entre os 12 passos propostos por Nakajima e o procedimento de implantação da TPM da empresa

12 PASSOS PROPOSTOS POR NAKAJIMA

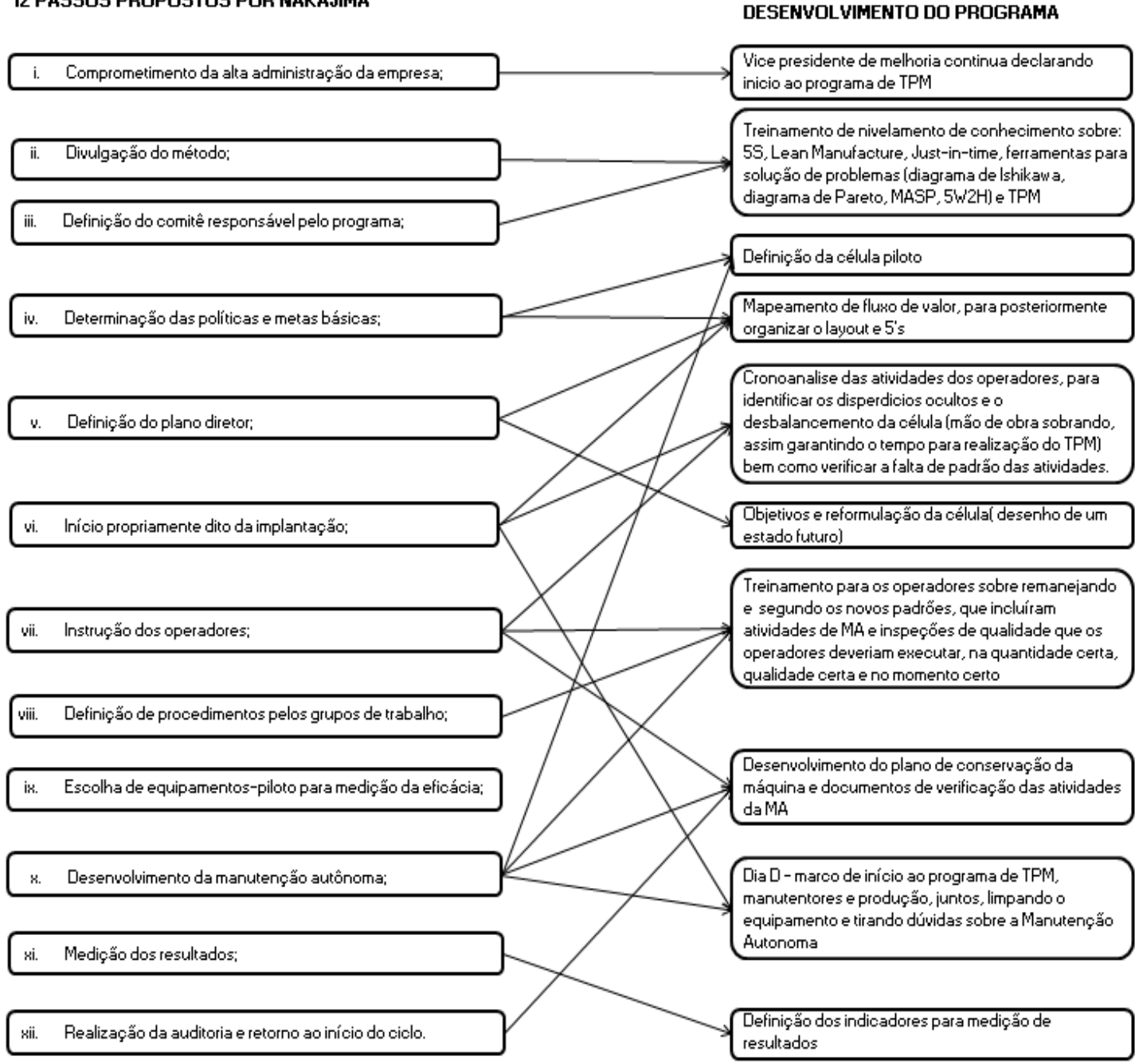

Fonte: Documentação interna da empresa estudada 


\section{RESULTADOS OBSERVADOS NOS EQUIPAMENTOS-PILOTO}

Para avaliar os resultados do programa, foram mensurados quatro indicadores: MTBF, MTTR, OEE, e custos de manutenção. Foram feitas mensurações antes do início do projeto, entre março de 2011 e março de 2012, e depois das atividades, entre maio de 2012 e maio de 2013. O mês de abril de 2012 foi um período de instabilidade e foi descartado da medição: em maio, foi iniciado o monitoramento da célula.

A Tabela 1 apresenta a média do MTBF dos três centros de usinagem que fizeram parte do estudo antes e depois do início do programa.

Tabela 1 - MTBF antes e depois da implantação da MA

\begin{tabular}{ccccc}
\hline & \multicolumn{2}{c}{ Antes } & \multicolumn{2}{c}{ Depois } \\
\cline { 2 - 5 } Equipamentos & Horas & Dias & Horas & Dias \\
\hline 25.890 & $21: 23: 00$ & 0,9 & $240: 07: 29$ & 10,0 \\
25.888 & $50: 23: 00$ & 2,1 & $343: 17: 52$ & 14,3 \\
25.885 & $48: 05: 00$ & 2,0 & $360: 05: 21$ & 15,0 \\
Média & $39: 83: 00$ & 1,7 & $314: 43: 34$ & 13,1 \\
\hline
\end{tabular}

Antes das atividades propostas pela $M A$, no pilar de manutenção autônoma, a célula apresentava uma média de tempo médio entre falhas muito menor do que depois da implantação do programa, ou seja, as falhas na célula ocorriam, em média, a cada 1,7 dias. Em particular, a máquina 25.890, que era o gargalo da célula, falhava em média mais do que uma vez por dia (MTBF = 0,9 dias). Um mês após o início do programa, começou-se a monitorar a célula e foi possível perceber o envolvimento de toda a equipe para resolver os problemas de manutenção antes mesmo que a máquina falhasse. Com isto, houve aumento do tempo médio entre falhas para 10 dias. Quando alguma anomalia era registrada, os manutentores utilizavam o horário de almoço da produção para resolver, não deixando que essa anomalia se tornasse uma falha e afetasse a disponibilidade do equipamento.

A Tabela 2 apresenta a média do MTTR dos três centros de usinagem que fizeram parte do estudo antes e depois do início do programa. 
Tabela 2 - MTTR antes e depois da implantação da MA

\begin{tabular}{ccccc}
\hline & \multicolumn{2}{c}{ Antes } & \multicolumn{2}{c}{ Depois } \\
\cline { 2 - 5 } Equipamentos & Horas & Min & Horas & Min \\
\hline 25.890 & $3: 23: 00$ & 203 & $2: 45: 00$ & 165 \\
25.888 & $1: 32: 00$ & 92 & $1: 13: 00$ & 73 \\
25.885 & $2: 15: 00$ & 135 & $1: 55: 00$ & 115 \\
Média & $2: 38: 00$ & 143 & $1: 58: 00$ & 118 \\
\hline
\end{tabular}

Houve diminuição das médias de tempo gasto para reparar os equipamentos, porque os operadores passaram a realizar pequenos reparos e a informar a manutenção quando verificavam pequenas anomalias no equipamento, ou seja, antes que houvesse uma grande falha.

A Tabela 3 apresenta a média dos custos com manutenção dos três centros de usinagem que fizeram parte do estudo antes e depois do início do programa.

Tabela 3 - Custos de manutenção antes e depois a implantação da MA

\begin{tabular}{ccc}
\hline & Antes & Depois \\
\hline Equipamentos & $\mathrm{R} \$$ & $\mathrm{R} \$$ \\
\hline 25.890 & 7.030 & 2.200 \\
25.888 & 5.340 & 3.505 \\
25.885 & 7.380 & 3.480 \\
Média & 6.583 & 3.061 \\
\hline
\end{tabular}

O custo de cada equipamento e o custo global da célula apresentaram expressiva redução. Os custos englobam tanto serviço quanto material. Porém não se pode deixar de mencionar que foi realizada manutenção preventiva, na qual houve um investimento considerável no mês de abril, com o objetivo de restaurar o desempenho nominal dos equipamentos.

A Tabela 4 apresenta a média do OEE dos três centros de usinagem no período de um ano anterior e posterior ao início do programa. 
Tabela 4 - OEE antes e depois da implantação da MA

\begin{tabular}{ccc}
\hline & Antes & Depois \\
\cline { 2 - 3 } Equipamentos & $\%$ & $\%$ \\
\hline 25.890 & 65 & 82 \\
25.888 & 82 & 94 \\
25.885 & 87 & 89 \\
Média & 78 & 88,3 \\
\hline
\end{tabular}

A meta da usinagem tem sido manter o OEE acima dos $85 \%$, o que é considerado por Nakajima (1993) como desempenho de classe mundial. Esta célula estava abaixo do esperado, com altos estoques de produtos acabados e de WIP (Work-in-Process, estoques entre processos), índice de horas extras acima do planejado e baixa confiabilidade no equipamento. Ou seja, um dos motivos predominantes para a baixa OEE da célula era a manutenção. Após o programa, pode-se perceber o aumento do OEE na célula, devido ao aumento de cerca de cinco pontos percentuais na disponibilidade de máquina $A v=$ MTBF/(MTBF+MTTR) e ao aumento da qualidade em partes por milhão (PPM) das peças produzidas. $O$ objetivo da empresa para a OEE foi atingido.

Após a consolidação do programa da MA conseguiu-se aumentar o índice de valor agregado (IVA) de $0,5 \%$ para $3 \%$ (IVA = tempo de ciclo/tempo de atravessamento), devido à redução na quantidade de estoque de peças entre as máquinas (WIP $=$ tempo de estoques entre máquinas/tempo de atravessamento). Com menos fila, obviamente diminuiu o tempo de espera por processamento e aumentou a agregação de valor. Adicionalmente, antes do programa, havia instabilidade na célula, ou seja, não se obtinha fluxo constante e equilibrado de peças, devido às quebras de máquinas. Após o início do programa, a célula como um todo e as máquinas individualmente apresentaram resultados mais estáveis.

Devido à estabilidade adquirida e ao aumento na disponibilidade da célula, foi possível uma redução na quantidade de horas trabalhadas para fabricar as peças necessárias. A célula passou de três turnos para dois turnos, além de eliminar as horas extras que frequentemente eram necessárias para atender a demanda da linha de produção e de peças de reposição. Com essa ação, reduziu-se o número de funcionários de nove para seis colaboradores, o que representou expressiva redução de custo na conta de mão-de-obra (Labor) da manufatura. 
A Tabela 5 sintetiza outros resultados importantes observados após a aplicação do programa.

Tabela 5 - Outros resultados antes e depois da implantação da MA

\begin{tabular}{cccc}
\hline Resultado & Antes & Depois & Variação \% \\
\hline Produtividade (peças/homem. hora) & 0,38 & 0,57 & $+50 \%$ \\
Refugos e retrabalhos (ppm) & 340 & 5 & $-98,5 \%$ \\
Inventário médio (ton.) & 2,5 & 2,2 & $-12 \%$ \\
Área utilizada (m ${ }^{2}$ ) & 240 & 220 & $-8 \%$ \\
Tempo de set-up médio (minutos) & 40 & 20 & $-50 \%$ \\
Disponibilidade média (\%) & 94,5 & 99,4 & $5,2 \%$ \\
\hline
\end{tabular}

\section{CONSIDERAÇÕES FINAIS}

O objetivo deste artigo foi descrever um caso de aplicação de manutenção autônoma em uma área piloto de uma empresa do ramo metal mecânico fabricante de máquinas agrícolas. O método de pesquisa foi o estudo de caso único. O objeto de estudo foi uma célula composta por três centros de usinagem de uma empresa fabricante de máquinas agrícolas. Foi implantado na empresa Beta um programa de TPM, que se iniciou pelo pilar da MA. O programa foi estruturado com base nos oito pilares e nos doze passos que Nakajima propôs, sendo a manutenção autônoma um guia para o sucesso do programa. No princípio, houve alguma relutância em alguns colaboradores em aceitar o programa, em especial a MA. Mas, com o aumento consistente da OEE e o programa de ideias, estabelecido pelo setor de melhoria contínua, que passou a remunerar funcionários proporcionalmente ao sucesso das iniciativas, houve mais adesão e conscientização acerca da TPM.

Os principais resultados do programa foram o aumento do MTBF e a redução do MTTR que, consequentemente, aumentaram tanto a disponibilidade dos equipamentos da célula-piloto como elevaram a OEE da célula. Os custos de manutenção reduziram-se significativamente, dado que diminuiu a compra de peças em regime de urgência e o número de quebras. Com isto, houve redução significativa de custos com materiais e com mão-deobra. A MA reduziu a quantidade de falhas crônicas nos equipamentos, que passaram a apresentar maior estabilidade e capabilidade nos processos, com 
reflexos significativos na qualidade dos produtos acabados e redução de retrabalho, reduzindo os estoques de produtos acabados e WIP. Com a TPM, o processo de usinagem da trombeta apresentou maior fluidez na célula-piloto, diminuindo o WIP, o tempo de atravessamento da peça na célula, e consequentemente aumentando o IVA (índice de valor agregado).

A conclusão que se pode chegar ao término deste estudo é que a manutenção, por meio da TPM e da MA, pode colaborar para a redução dos custos de manufatura da empresa e com isto contribuir para uma eventual estratégia de produção baseada em redução de custos. Para novos estudos, sugere-se o acompanhamento sistemático da introdução da MA em novas células e o acompanhamento dos demais passos da TPM nas demais instalações da empresa.

\section{Reconhecimentos}

Parte da pesquisa foi financiada pelo CNPq.

\section{REFERÊNCIAS}

ALBERTIN, M.; SAMPAIO, C.; DIAS, M.; FEITOSA, P. Aplicação da Eficiência Global de Equipamentos com Indicador de Qualidade Sem Perdas. Anais do XXXII ENEGEP, Encontro Nacional de Engenharia de Produção, ABEPRO, Bento Gonçalves: 2012.

BAMBER, C.; SHARP, J.; HIDES, M. Factors affecting successful implementation of total productive maintenance a UK manufacturing case study perspective, Journal of Quality in Maintenance Engineering, v. 5, n. 3, p. 162-181, 1999.

http://dx.doi.org/10.1108/13552519910282601

BOER, H.; GERTSEN, F. From continuous improvement to continuous innovation: a (retro)(per) spective, International Journal of Technology Management, v.26, n.8, p.805-827, 2003. http://dx.doi.org/10.1504/IJTM.2003.003391

BORCHARDT, M.; SELLITTO, M.; PEREIRA, G. Serviços de pós-venda para produtos fabricados em base tecnológica. Produção Online, v.8, n.2, p.1-26, 2008.

http://dx.doi.org/10.14488/1676-1901.v8i2.121

BORCHARDT, M.; SELLITTO, M.; PEREIRA, G. Sistemas Produto-Serviço: referencial teórico e direções para futuras pesquisas. Produção Online, v.10, n.4, p.837-860, 2010. http://dx.doi.org/10.14488/1676-1901.v10i4.510

CONCEIÇÃO JR, J.; SILVA, S. Educação e treinamento como fator crítico para a Manutenção Autônoma (MA): estudo de caso de implementação do Total Productive 
Maintenance (TPM). Anais do XII SIMPOI, Simpósio de Administração da Produção, Logística e Operações Internacionais, FGV, São Paulo: 2010.

FERREIRA, T.; MOREIRA, D.; DISCONZI, C. Análise da Produtividade de Uma Empresa de Beneficiamento de Arroz Através do Índice de Rendimento Global. Anais do XXXII ENEGEP, Encontro Nacional de Engenharia de Produção, ABEPRO, Bento Gonçalves: 2012.

GOMES, M.; LIMA, C.; SILVA I. Implantação da lubrificação autônoma como Ferramenta Essencial do TPM Uma Abordagem Prática, Anais do XXXII ENEGEP, Encontro Nacional de Engenharia de Produção, ABEPRO, Bento Gonçalves: 2012.

KARDEC, A.; NASCIF, J. Manutenção Função Estratégica. Rio de Janeiro: Qualitymark, 2001.

KATKAMWAR, S.; WADATKAR, S.; PAROPATE, R. Study of Total Productive Maintenance \& Its Implementing Approach in Spinning Industries, Internantional Journal of Engineering Trends and Technology, v.4, n.5, p. 1750-1754, 2013.

$\mathrm{KOCH}, \mathrm{A}$. Discover the hidden machine: OEE for production team. Amsterdam: FullFact BV, 2007.

LAZIM, H.; RAMAYAH, T.; AHMAD, N. Total productive maintenance and performance: A Malaysian SME experience. International Review of Business Research Paper, v.4, n.4, p.237-250, 2008.

LIKER, J. O Modelo Toyota - 14 Princípios de Gestão do Maior Fabricante do Mundo. Porto Alegre: Bookman, 2005.

MCKONE, K.; SCHROEDER, R.; CUA, K. The impact of total productive maintenance practices on manufacturing performance, Journal of Operations Management, v.19, n.1, p.39-58, 1999. http://dx.doi.org/10.1016/S0272-6963(00)00030-9

MCKONE, K.; SCHROEDER, R.; CUA, K. Total productive maintenance: a contextual view, Journal of Operations Management, v.17, n.2, p.123-144, 1998.

http://dx.doi.org/10.1016/S0272-6963(98)00039-4

MONTEIRO JR., A.; MOTTA, D.; SILVA, D.; MONTEIRO, D. Proposta de Aumento de Eficiência Fabril por Meio da Manutenção Produtiva Total em uma Empresa Fabricante de Embalagem de Alumínio, Anais do XXXII ENEGEP, Encontro Nacional de Engenharia de Produção, Bento Gonçalves: ABEPRO, 2012.

NAKAJIMA, S. Introduction to Total Productive Maintenance (TPM) Cambridge: Productivity Press, 1988.

NAKAZATO, K. Manual de Implementação do TPM. Nagoya: JIPM, Japan Institute of Plant Maintenance, 1999.

OHNO, T. Just In Time for Today and Tomorrow. Cambridge: Productivity Press, 1986.

OHNO, T. O Sistema Toyota de Produção: além da produção em larga escala. Porto Alegre: Bookmann, 1997.

OHNO, T. Workplace Management. Cambridge: Productivity Press, 1998. 
PACHECO, D.; ANTUNES JÚNIOR, J.; LACERDA, D.; GOLDMEYER, D.; GILSA, C.; Modelo de gerenciamento da capacidade produtiva: integrando teoria das restrições e o índice de rendimento operacional global (IROG). Produção Online, v.12, n.3, p. 806-826, 2012. http://dx.doi.org/10.14488/1676-1901.v12i3.981

PETTER, R.; RESENDE, L.; SELIG, P.; VAZ, C. Produção Limpa, Produção mais Limpa, Produção Enxuta, 5S e Manutenção Autônoma - Uma Proposta Metodológica de Implantação Conjunta", Anais do VII CNEG, Congresso Nacional de Excelência em Gestão, UFF, Rio de Janeiro: 2011.

RAPOSO, C. Overall Equipment Effectiveness: Aplicação em uma empresa do setor de bebidas do pólo industrial de Manaus. Produção Online, v.11, n.3, p.648-667, 2011. http://dx.doi.org/10.14488/1676-1901.v11i3.529

RON, A.; ROODA, J. Equipment effectiveness: OEE revisited. IEEE Transactions on Semiconductor Manufacturing, v.18, n.1, p.190-196, 2005.

http://dx.doi.org/10.1109/TSM.2004.836657

SELLITTO, M. Inteligência artificial: uma aplicação em uma indústria de processo contínuo. Gestão \& Produção, v.9, n.3, p.363-376, 2002.

http://dx.doi.org/10.1590/S0104-530X2002000300010

SELLITTO, M. Formulação estratégica da manutenção industrial com base na confiabilidade dos equipamentos, Produção, v.15, n.1, p.44-59, 2005.

http://dx.doi.org/10.1590/S0103-65132005000100005

SELLITTO, M.; BORCHARDT, M.; ARAÚJO, D. Manutenção Centrada em Confiabilidade Aplicando Uma Abordagem Quantitativa, Anais do XXII ENEGEP, Encontro Nacional de Engenharia de Produção, ABEPRO, Curitiba: 2002.

SHINGO, S. O Sistema Toyota de Produção do Ponto de Vista da Engenharia de Produção. Porto Alegre: Bookmann, 1996.

SILVA FILHO, O.; SELLITTO, M. Cálculo da disponibilidade e posição no ciclo de vida de três linhas de produção de uma empresa da indústria química. Engevista, v.16, n. 4, p.414-430, 2014.

SURESH, P. TPM Implementation in a Food Industry - A PDCA Approach, International Journal of Scientific and Research Publications, v.2, n.11, p.1-9, 2012.

SUZUKI, T. TPM in process industries. Portland: Productive Press, 1994.

SWANSON, L. Linking maintenance strategies to performance, International Journal of Production Economics, v.70, n.3, p. 237-244, 2001.

http://dx.doi.org/10.1016/S0925-5273(00)00067-0

TAKAHASHI, Y.; OSADA, T. TPM: Manutenção Produtiva Total. São Paulo: Instituto IMAM, 1993.

TAVARES, L. Administração moderna da manutenção. Rio de Janeiro: Novo Polo, 1999. 
WAKJIRA, M.; SINGH, A. Total productive maintenance: A case study in manufacturing industry, Global Journal of Researches in Engineering, v.12, n.1, p.25-32, p., 2012.

XENOS, H. Gerenciando a Manutenção Produtiva. Belo Horizonte: Editora da Fundação de Desenvolvimento Gerencial, 1998.

ZATTAR, I.; RUDEK, S.; TURQUINO, G. O Uso do Indicador OEE Como Ferramenta da Tomada de Decisões em uma Indústria Gráfica - Um Caso Prático, Iberoamerican Journal of Industrial Engineering, v.2, n.4, p. 113-132, 2011.

http://dx.doi.org/10.13084/2175-8018.v02n04a06

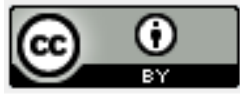

Artigo recebido em 09/05/2015 e aceito para publicação em 22/09/2015

DOI: $\underline{\text { http://dx.doi.org/ 10.14488/1676-1901.v16i2.2048 }}$ 